\title{
INFLuênCIA do Estádio DE DESEnvolvimento DE Cenchrus echinatus NA SUPRESSÃo IMPOSTA POR ATRAZINE ${ }^{1}$
}

\author{
Effect of the Growth Stage of Cenchrus echinatus on Weed Suppression Imposed by Atrazine
}

\author{
DAN, H.A. ${ }^{2}$, DAN, L.G.M. ${ }^{3}$, BARROSO, A.L.L. ${ }^{4}$, OLIVEIRA JR., R.S. ${ }^{5}$, ALONSO, D.G. ${ }^{6}$ e \\ FINOTTI, T.R. ${ }^{7}$
}

\begin{abstract}
RESUMO - Cenchrus echinatus é uma importante infestante em áreas de cultivo de milho, sorgo e milheto no Brasil. Embora atrazine seja um dos herbicidas mais utilizados nessas culturas, pouco tem sido feito para determinar a suscetibilidade dessa espécie em função do seu estádio de desenvolvimento em aplicações em pós-emergência. O presente trabalho teve por objetivo avaliar a supressão imposta pelo atrazine, aplicado em pós-emergência, em três estádios de desenvolvimento dessa planta daninha. O ensaio foi implantado em unidades de $10 \mathrm{dm}^{-3}$ de solo, em casa de vegetação, em esquema fatorial $5 \times 3$, com quatro repetições, correspondendo a cinco doses de atrazine $\left(0 ; 0,5 ; 1,5 ; 2,5 ;\right.$ e $\left.4,0 \mathrm{~kg} \mathrm{ha}^{-1}\right)$, combinadas com três estádios de desenvolvimento de C. echinatus (um par de folhas, dois pares de folhas e dois afilhos) por ocasião da aplicação do herbicida em pós-emergência. Aplicações realizadas em estádios mais tardios foram ineficientes no controle dessa espécie, apesar de causarem reduções significativas no acúmulo de biomassa seca, na altura das plantas e na produção de estruturas reprodutivas. Visando controlar essa espécie, os melhores resultados são obtidos com aplicações de doses a partir de $3,5 \mathrm{~kg} \mathrm{ha}^{-1}$ em plantas com um par de folhas.
\end{abstract}

Palavras-chave: capim-carrapicho, pós-emergência, Poaceae, triazinas.

\begin{abstract}
Cenchrus echinatus is an important weed in areas cultivated with corn, sorghum and pearl millet in Brazil. Although atrazine is one of the most used herbicides in such crops, not much has been done to determine weed susceptibility as a function of its growth stage at postemergence applications. This work aimed to evaluate the suppression imposed by the herbicide atrazine applied at post-emergence, during three developmental stages of this weed. The assay was carried out under greenhouse conditions, in pots of $10 \mathrm{dm}^{-3}$, in a factorial scheme $5 \times 3$ composed by five rates of atrazine $\left(0 ; 0.5 ; 1.5 ; 2.5\right.$ and $\left.4.0 \mathrm{~kg} \mathrm{ha}^{-1}\right)$, combined with three stages of C. echinatus development during herbicide spraying at post-emergence (first pair ofleaves; second pair of leaves and two tillers). Applications performed at later stages of weed development were inefficient to provide control, despite significant reductions of dry biomass, plant height and production of reproductive structures. Aiming at weed control, the best results were found for rates $\geq 3.5 \mathrm{~kg} \mathrm{ha}^{-1}$ in plants at the stage of first pair of leaves.
\end{abstract}

Keywords: Sandbur, post-emergence, Poaceae, triazines.

\section{INTRODUÇÃO}

O capim-carrapicho ou timbete (Cenchrus echinatus) é uma gramínea herbácea de ocorrência bastante generalizada em todo o Brasil, sendo considerada uma das seis espécies mais agressivas na agricultura moderna (Pacheco \& Marinis, 1984). É uma planta de

1 Recebido para publicação em 18.5.2010 e na forma revisada em 18.2.2011.

2 Doutorando do Programa de Pós-Graduação em Agronomia, Universidade Estadual de Maringá - UEM/NAPD, Av. Colombo 5790, 87020-900 Maringá-PR, <halmeidadan@gmail.com>; ${ }^{3}$ Mestranda, Programa de Pós-Graduação em Agronomia, UEM; ${ }^{4}$ Professor do Programa de Pós-Graduação em Produção Vegetal, Universidade de Rio Verde - FESURV, Caixa Postal 104, 75901-970 RioVerde-GO; ${ }^{5}$ Professor do Dep. de Agronomia, UEM/NAPD; ${ }^{6}$ Doutorando, Programa de Pós-Graduação em Agronomia, UEM; ${ }^{7}$ Graduado em Agronomia, FESURV. 
elevado potencial competitivo, podendo causar danos diretos e indiretos às culturas. Apresenta crescimento inicial lento, folhas alternadas dísticas, lanceoladas e paralelinérveas. Sua reprodução ocorre via semente e seus frutos (cariopse) apresentam grande potencial de dispersão (Kissmann, 1997). Cada planta pode chegar a produzir cerca de 300 fascículos durante todo o seu ciclo de vida (Pacheco \& Marinis, 1984). Cada fascículo pode germinar a uma profundidade de até $11 \mathrm{~cm}$ (Deuber et al., 1977).

Além de ser uma importante infestante, tanto em cultivos no verão quanto na "safrinha" (Duarte et al., 2007), é uma das plantas de maior dificuldade de controle na cultura do sorgo (Abit et al., 2009) e do milheto, constituindo-se num grande problema na região dos cerrados, devido à limitada disponibilidade de herbicidas com ação graminicida registrados e que apresentam seletividade para essas culturas.

Um dos herbicidas mais utilizados para o controle de plantas daninhas em pós-emergência nas culturas do sorgo, milheto e milho é o atrazine. Trata-se de herbicida cujo mecanismo de ação inibe o fotossistema II e que apresenta boa seletividade para as culturas do milho e sorgo (Silva et al., 2007); pode ser usado tanto de forma isolada (Fornarolli et al., 1999; Maciel et al., 2002) quanto em associação com outros herbicidas, como mesotrione (Timossi, 2009), tembotrione (Bollman et al., 2008) e nicosulfuron (Rizzardi et al., 2008), para o controle de plantas daninhas na cultura do milho.

Atrazine é normalmente recomendado para uso em pré-emergência, porém pode ser usado em pós-emergência, desde que a aplicação seja feita nos estádios iniciais de desenvolvimento das plântulas (Gopinath \& Kundu, 2008). Para essa modalidade de aplicação, é necessária a adição de adjuvantes adequados, a fim de aumentar a absorção foliar, uma vez que a via principal de absorção é a radicular (Maciel et al., 2002).

Com relação ao controle de gramíneas, Fornarolli et al. (1999) obtiveram niveis aceitáveis de controle de Brachiaria plantaginea com o uso de atrazine, na dose de $3,0 \mathrm{~kg} \mathrm{ha}^{-1}$, aplicado no estádio de três folhas. Em contrapartida, esse herbicida não interferiu no desenvolvimento e no estabelecimento de Brachiaria decumbens em condições de pastagem (Martins et al., 2007). A aplicação de atrazine em pré-emergência controlou de forma mais eficiente Echinochloa colona do que em pós-emergência (Gopinath \& Kundu, 2008). Para Maciel et al. (2002), além do estádio das plantas daninhas, a utilização de adjuvantes tem papel importante na eficiência do atrazine; aplicações tardias (quatro folhas) reduziram o controle de $B$. plantaginea.

Apesar de utilizado em larga escala, são escassas as informações referentes ao efeito de atrazine sobre espécies como Cenchrus echinatus. Nesse contexto, objetivou-se neste trabalho avaliar a supressão imposta pelo atrazine, aplicado em pós-emergência, em três estádios de desenvolvimento dessa planta daninha.

\section{MATERIAL E MÉTODOS}

O experimento foi conduzido em casa de vegetação no campus da Faculdade de Agronomia da FESURV-Universidade de Rio Verde, em Rio Verde-GO, localizada nas coordenadas de $17^{\circ} 48^{\prime} \mathrm{S}, 5^{\circ} 55^{\prime} \mathrm{W}$ e altitude de $760 \mathrm{~m}$, durante o período de agosto a novembro de 2008. O clima da região é caracterizado como úmido tropical, com duas estações bem definidas: seca no inverno e úmida no verão (Roberto, 2002).

As unidades experimentais foram compostas de vasos de $10 \mathrm{dm}^{3}$ de capacidade, preenchidos com Latossolo Vermelho distroférrico de textura argilosa, coletado na camada de 20 a $40 \mathrm{~cm}$ de profundidade. As características químicas e fisicas da amostra do solo foram: pH em água: 4,4; Ca: $1,36 \mathrm{cmol}_{\mathrm{c}} \mathrm{dm}^{-3}$; $\mathrm{Mg}$ : $0,73 \mathrm{cmol}_{\mathrm{c}} \mathrm{dm}^{-3} ; \mathrm{Al}: 0,45 \mathrm{cmol}_{\mathrm{c}} \mathrm{dm}^{-3} ; \mathrm{H}+\mathrm{Al}$ : $4,8 \mathrm{cmol}_{\mathrm{c}} \mathrm{dm}^{-3}$; K: $65 \mathrm{mg} \mathrm{dm}^{-3}$; P: 2,07 $\mathrm{mg} \mathrm{dm}^{-3}$; CTC: $16,6 \mathrm{cmol}_{\mathrm{c}} \mathrm{dm}^{-3}$; MO: 21,67 $\mathrm{g} \mathrm{kg}^{-1}$; argila: $600 \mathrm{~g} \mathrm{~kg}^{-1}$; silte: $50 \mathrm{~g} \mathrm{~kg}^{-1}$; e areia: $350 \mathrm{~g} \mathrm{~kg}^{-1}$.

A correção da acidez do solo foi realizada 30 dias antes da semeadura de Cenchrus echinatus, utilizando-se o equivalente a 1,78 tonelada de calcário dolomítico (PRNT $98 \%)$ por hectare. No momento da semeadura, realizou-se uma adubação de base com $50 \mathrm{~kg} \mathrm{ha}^{-1}$ de $\mathrm{P}_{2} \mathrm{O}_{5}$ (superfosfato simples), $20 \mathrm{~kg} \mathrm{ha}^{-1}$ de $\mathrm{K}_{2} \mathrm{O}$ (cloreto de potássio) e $20 \mathrm{~kg} \mathrm{ha}^{-1}$ de nitrogênio (sulfato de amônia). 
O ensaio foi conduzido no delineamento inteiramente casualizado com quatro repetições, em esquema fatorial $5 \times 3$, correspondendo a cinco doses de atrazine (Atrazina Nortox 500 SC) nas doses de $0 ; 0,5 ; 1,5 ; 2,5$; e $4,0 \mathrm{~kg} \mathrm{ha}^{-1}$, aplicadas em três estádios fenológicos da planta daninha: estádio 1 (plântulas com duas folhas, 12 dias após a emergência); estádio 2 (plantas com quatro folhas, 18 dias após a emergência); e estádio 3 (plantas com um a dois afilhos, cerca de 28 dias após a emergência). Em todos os tratamentos herbicidas foi adicionado à calda $0,5 \% \mathrm{v} / \mathrm{v}$ do óleo mineral Attach.

As sementes de C. echinatus foram obtidas por meio de coleta em campo e semeadas a $2,5 \mathrm{~cm}$ de profundidade. Logo após a emergência, as plântulas foram desbastadas, para que fossem mantidas três plantas por unidade experimental.

A aplicação do herbicida nas diferentes doses foi feita com pulverizador costal com pressurização por $\mathrm{CO}_{2}$, munido de quatro pontas de pulverização do tipo TT 110-02 (barra de $2 \mathrm{~m}$ e $0,5 \mathrm{~m}$ entre pontas), utilizando um volume de calda equivalente a $100 \mathrm{~L} \mathrm{ha}^{-1}$. As condições ambientais no momento das aplicações eram as seguintes: estádio 1 (temperatura média de $29,1{ }^{\circ} \mathrm{C}$, UR de $71 \%$ e velocidade do vento de 2,9 $\mathrm{km} \mathrm{h}^{-1}$ ); estádio 2 (temperatura média de $25,2{ }^{\circ} \mathrm{C}$, UR de $81 \%$ e velocidade do vento de $2,4 \mathrm{~km} \mathrm{~h}^{-1}$ ); e estádio 3 (temperatura média de $25,7^{\circ} \mathrm{C}$, UR de $77 \%$ e velocidade do vento de $3,8 \mathrm{~km} \mathrm{~h}^{-1}$ ). Todas as aplicações foram iniciadas no mesmo horário, $7 \mathrm{~h} 30 \mathrm{~min}$, justamente devido às melhores condições para aplicação. A irrigação foi retomada 24 horas após a aplicação dos tratamentos, com o intuito de evitar perdas do herbicida por lavagem foliar.

As avaliações de controle foram realizadas aos 7 e 21 dias após a aplicação dos tratamentos (DAA), utilizando-se escala percentual de 0 a $100 \%$, em que 0 representa ausência de sintomas e $100 \%$ a morte de todas as plantas. Foram determinados ainda o número de afilhos por planta e a altura das plantas (medida com uma régua do colo da planta à extremidade final do cacho), aos 85 dias após a emergência. No final da fase reprodutiva obteve-se o número de cachos por planta, a massa dos cachos (sem o pedúnculo) e a biomassa seca acumulada da parte aérea, obtida após a colheita e secagem em estufa com circulação de ar a $65^{\circ} \mathrm{C}$ durante um periodo de 72 horas.

Os resultados referentes aos niveis de controle foram submetidos à transformação $(\sqrt{ }+1)$ para seguir os pressupostos necessários à análise de variância, que foi realizada com o programa estatístico Sisvar. Foram ajustados modelos lineares de regressão para as variáveis-resposta que apresentaram significância, utilizando-se posteriormente o programa Sigma Plot versão 10.0 para confecção das curvas de regressão.

\section{RESULTADOS E DISCUSSÃO}

Houve interação significativa entre as doses de atrazine e os estádios de desenvolvimento de Cenchrus echinatus, em relação às duas avaliações de controle visual. Dentro do intervalo de doses estudado, observaram-se inicialmente (7 DAA) controles máximos de 76 e $37 \%$, respectivamente, para aplicações realizadas nos estádios 1 e 3 . Aos 21 dias após a aplicação (DAA), a tendência foi a mesma, isto é, aplicações realizadas em estádios mais precoces de desenvolvimento do $C$. echinatus apresentaram taxas de controle maiores do que aplicações realizadas mais tardiamente (Figura 1).

Comparando os coeficientes angulares das regressões ajustadas (Figura 1B), observa-se que, embora em todos os casos a porcentagem de controle seja diretamente proporcional à dose de atrazine aplicada, plantas que receberam o herbicida no estádio 1 (plântulas com duas folhas) apresentaram incrementos de controle em função da dose numa taxa aproximadamente duas vezes maior do que aqueles que receberam a aplicação no estádio 3 (plantas com um a dois afilhos). Embora a ação de atrazine em pós-emergência seja mais de contato do que sistêmica, é possivel notar que na avaliação realizada aos 21 DAA houve significativa melhora no controle das plantas que receberam o herbicida no estádio 1 , obtendo-se controles $\geq 80 \%$ com doses a partir de $3,0 \mathrm{~kg} \mathrm{ha}^{-1}$, ao passo que, mesmo com a utilização de doses de até $4,0 \mathrm{~kg} \mathrm{ha}^{-1}$, não foi possivel obter esse mesmo nivel de controle para aplicações em estádios mais tardios. 

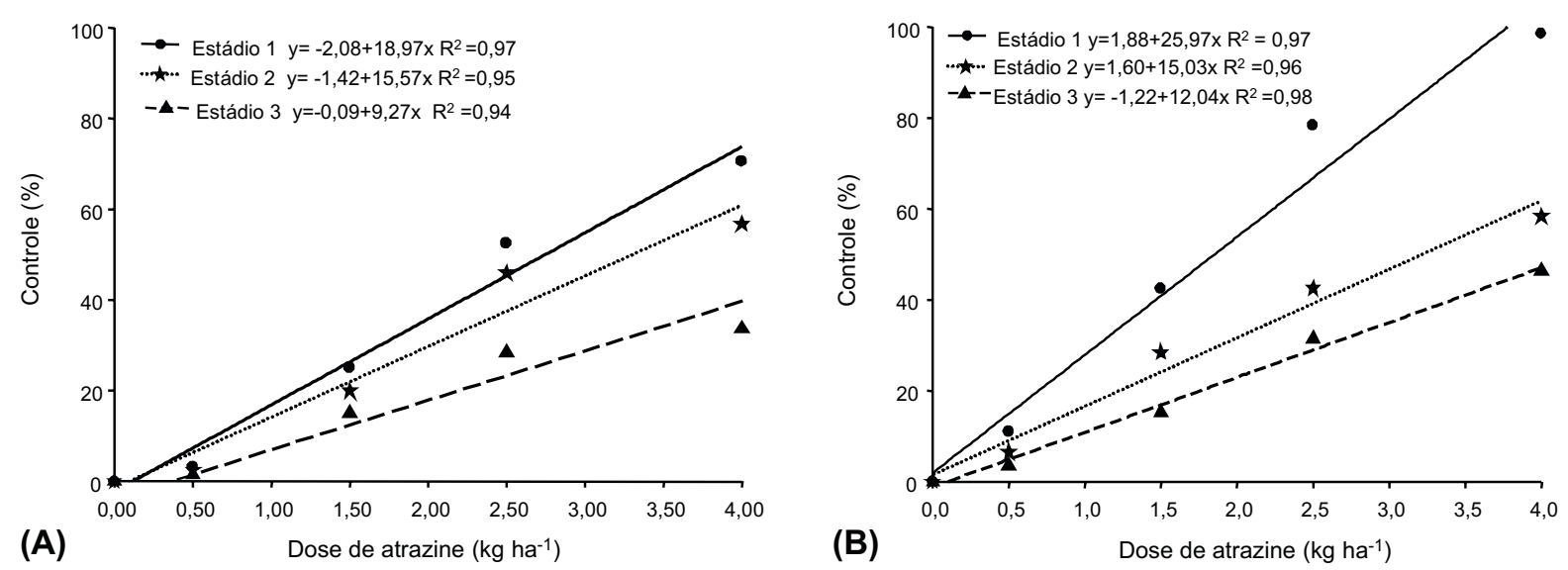

Figura 1 - Controle de Cenchrus echinatus em função das doses de atrazine aos 7 (A) e 21 (B) dias após a aplicação (DAA), para diferentes estádios de aplicação do herbicida

Durante o período de avaliação, os sintomas mais evidentes apresentados pelas plantas de C. echinatus foram clorose internervural seguida de necrose nos bordos das folhas; para Weller (2003), trata-se de sintoma característico dos herbicidas inibidores do fotossistema II. Em plantas mais sensiveis, essa sintomatologia pode ser expressiva logo aos quatro dias após a aplicação.

É possivel observar que o controle efetivo em estádios mais avançados de desenvolvimento é muito dificultado devido ao grau de tolerância que a espécie adquire progressivamente. Segundo Silva et al. (2007), uma das explicações plausiveis para esse aumento na tolerância em gramíneas relaciona-se à menor absorção através dos tecidos foliares ou mesmo à existência de compostos, como benzoxazinonas, capazes de proporcionar reações como hidroxilação, dealquilação e até mesmo conjugação, reduzindo a atividade do herbicida. Para Marcacci et al. (2005), o citocromo P450 é o grande responsável pela dealquilação do herbicida em plantas tolerantes. Prado et al. (1995) constataram que a seletividade de atrazine para Panicum dichotomiflorum ocorreu devido ao processo de conjugação com os compostos cisteína e glutationa.

Além do estádio das plantas no momento da aplicação, é possivel haver diferenças marcantes entre espécies pertencentes à família Poaceae no que se refere à intoxicação provocada por atrazine. Martins et al. (2007), por exemplo, constataram que Brachiaria brizanta possui maior sensibilidade a atrazine do que Brachiaria decumbens. Já $D$. horizontalis mostrou ser insensivel quando esse herbicida é usado de forma isolada em sistema de integração lavoura-pecuária (Jakelaitis et al., 2005).

A altura das plantas pode ser considerada uma propriedade fundamental no processo de dispersão da espécie, já que plantas com racemos de maior comprimento possuem eventualmente maior amplitude para distribuição dos fascículos. A utilização de atrazine, independentemente da dose ou do estádio de desenvolvimento de $C$. echinatus no momento da aplicação, promove supressão do crescimento dessa espécie. O nível de supressão da altura final é diretamente proporcional à dose e inversamente proporcional à idade das plantas no momento da aplicação (Figura 2).

Os efeitos relacionados à ação do herbicida nas plantas não se restringiram apenas à altura das plantas. É possivel observar ainda que a elevação da dose reduziu substancialmente o afilhamento das plantas (Figura 3). Plantas livres da ação do herbicida chegaram a produzir 25 afilhos, decrescendo numa taxa de 6,94, 4,87 e 3,05 para cada incremento na dose equivalente a $1 \mathrm{~kg} \mathrm{ha}^{-1}$ do herbicida para os estádios 1, 2 e 3, respectivamente. Em função desses valores, é possivel inferir que aplicações mais tardias apresentam menores efeitos sobre esse aspecto biológico da espécie.

É interessante salientar que a quantidade de afilhos viáveis pode ser um fator determinante sobre o número de estruturas reprodutivas, uma vez que as plantas com maior 
número de afilhos eventualmente terão uma capacidade de produzir maior número de racemos e, consequentemente, de fascículos.

Ao analisar os percentuais de acúmulo na matéria seca em relação aos valores apresentados pela testemunha (Figura 4), constata-se que as maiores reduções foram observadas quando a aplicação do herbicida ocorreu no estádio 1. Para aplicações neste estádio, o acréscimo de cada kg de herbicida proporciona decréscimo de $25,07 \%$ na biomassa seca acumulada durante todo o ciclo de vida da planta. Para os demais estádios, as taxas de redução são de 21 a $22 \%$. Para se obter redução de $80 \%$ da biomassa da planta, foi necessário

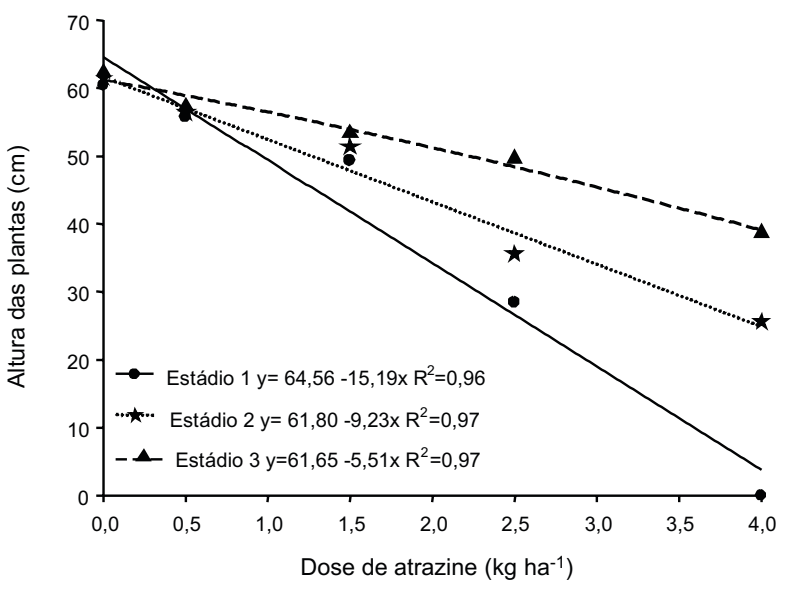

Figura 2 -Altura das plantas de Cenchrus echinatus aos 85 dias após a emergência (DAE), em função da dose de atrazine e do estádio da planta daninha no momento da aplicação.

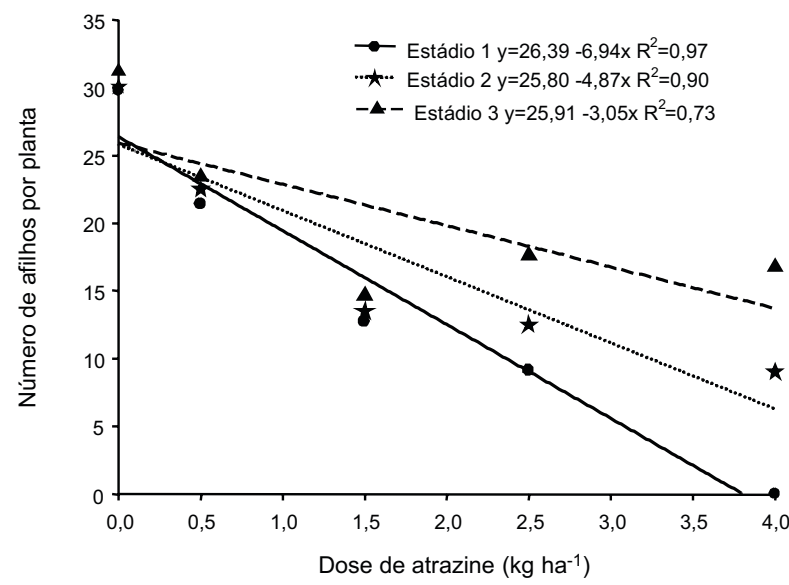

Figura 3 - Número de afilhos por planta de C. echinatus aos 85 dias após a emergência em, função da dose de atrazine e do estádio da planta daninha no momento da aplicação

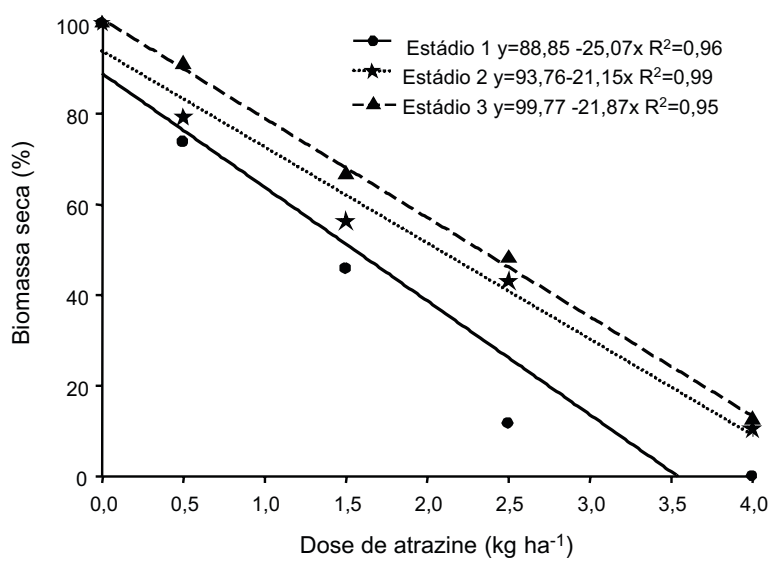

Figura 4 - Acúmulo de biomassa seca (\% em relação à testemunha), observada em plantas de C. echinatus aos 105 dias após a emergência, em função da dose de atrazine e do estádio da planta daninha no momento da aplicação.

utilizar de 2,7, 3,4 e 3,6 $\mathrm{kg} \mathrm{ha}^{-1}$ de atrazine para aplicações nos estádios 1, 2 e 3, respectivamente.

Tratando-se dos aspectos reprodutivos, as plantas de C. echinatus mostraram reduções expressivas tanto no número quanto na massa dos cachos (Figura 5A) quando expostas a doses crescentes de atrazine. O estresse causado pelo herbicida proporcionou reduções lineares de 4,57, 3,91 e 3,92 cachos para cada $\mathrm{kg}$ do herbicida adicionado à dose nos estádios $1,2 \mathrm{e}$ 3 , respectivamente.

A massa das estruturas reprodutivas seguiu a mesma tendência observada em todas as variáveis e apresentadas anteriormente (Figura 5B). Além do menor número de estruturas reprodutivas, as massas dos cachos tiveram reduções expressivas com a elevação das doses, com efeitos mais supressivos nas aplicações nos estádios iniciais de desenvolvimento da plântula. Para as duas variáveisresposta, o único estádio de aplicação no qual foi possivel obter $80 \%$ de redução da massa e do número de racemos dentro do intervalo de doses avaliado foi o 1 , necessitando de no minimo $3,0 \mathrm{~kg} \mathrm{ha}^{-1}$ de atrazine.

O presente trabalho demonstrou que aplicações de atrazine realizadas em pós-emergência nos estádios iniciais de desenvolvimento apresentam maior efeito supressor sobre C. echinatus. Para aplicações realizadas em plantas com um par de folhas, é possivel obter 

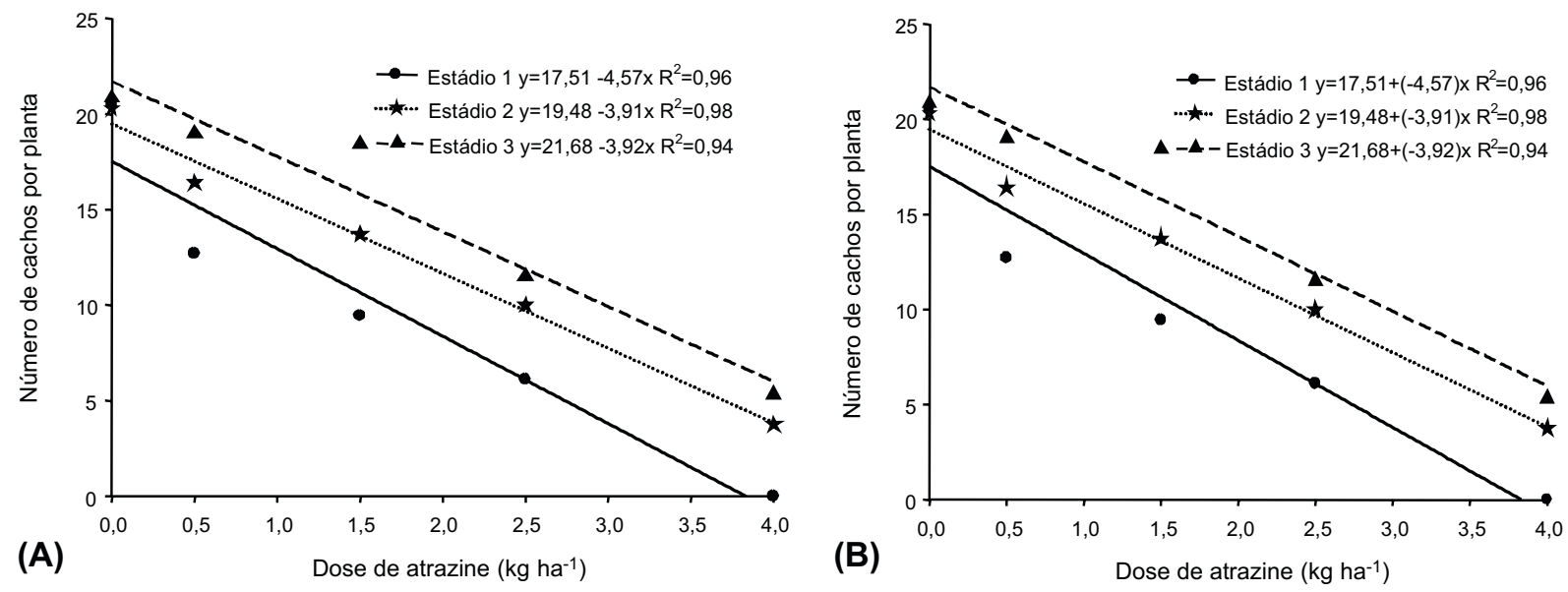

Figura 5 - Número (A) e massa (B) dos racemos por planta de C. echinatus aos 105 dias após a emergência, em função da dose de atrazine e do estádio da planta daninha no momento da aplicação.

controle superior a $90 \%$ com doses a partir de $3,5 \mathrm{~kg} \mathrm{ha}^{-1}$.

\section{LITERATURA CITADA}

ABIT, J. M. et al. Differential response of grain sorghum hybrids to foliar-applied mesotrione. Weed Technol., v. 23, n. 1, p. $28-33,2009$

BOLLMAN, J. D. et al. Efficacy and tolerance to HPPDinhibiting herbicides in sweet corn. Weed Technol., v. 22, n. 4, p. 666-674, 2008.

DUARTE, A. P.; SILVA, A. C.; DEUBER, R. Plantas infestantes em lavouras de milho-safrinha, sob diferentes manejos, no médio Paranapanema. Planta Daninha, v. 25, n. 2, p. 285-281, 2007.

DEUBER, R.; FOSTER, R.; SIGNORI, L. H. Efeito de herbicidas na anatomia de capim carrapicho e amendoimbravo. Bragantia, v. 36, n. 1, p. 207-213, 1977

FORNAROLLI, D. A. et al. Influência do horário de aplicação no comportamento de atrazine e misturas aplicadas em pósemergência na cultura do milho. Planta Daninha, v. 17, n. 1, p. 119-120, 1999.

GOPINATH, K. A.; KUNDU, S. Effect of dose and time of atrazine application on weeds in maize (Zea mays) under midhill conditions of northwestern himalayas. Indian J. Agric. Sci., v. 78, n. 3, p. 254-257, 2008.

KISSMANN, K. G. Plantas infestantes e nocivas. São Paulo: BASF, 1997. 824 p

JAKELAITIS, A. et al. Efeitos de herbicidas no consórcio de milho com Brachiaria brizantha. Planta Daninha, v. 23, n. 1, p. $69-78,2005$
MACIEL, C. D. G. et al. Método alternativo para avaliação da absorção de atrazine por plantas de Brachiaria plantaginea. Planta Daninha, v. 20, n. 3, p. 431-438, 2002

MARCACCI, S. et al. The possible role of hydroxylation in the detoxification of atrazine in mature vetiver (Chrysopogon zizanioides Nash) grown in hydroponics. J. Biosci., v. 60, n. 5, p. 427-34, 2005

MARTINS, D. et al. Seletividade de herbicidas aplicados em pós-emergência sobre capim-braquiária. R. Bras. Zootec., v. 36, n. 6, p. 1969-1974, 2007.

PACHECO, R. P. B.; MARINIS, G. Ciclo de vida, estruturas reprodutivas e dispersão de populações experimentais de capim-carrapicho (Cenchrus echinatus). Planta Daninha, v. 7, n. 1, p. $58-64,1984$

PRADO, R.; ROMERA, E.; MENENDEZ, J. Atrazine detoxification in Panicum dichotomiflorum and target site Polygonum lapathifolium. Pest. Biochem. Phys., v. 52, n. 1, p. 1-11, 1995.

ROBERTO, P. A. Agrometeorologia agrícola. Cuiabá: Agropecuária, 2002. $479 \mathrm{p}$

RIZZARDI, M. A. et al. Controle de plantas daninhas em milho em função de épocas de aplicação de nitrogênio Planta Daninha, v. 26, n. 1, p. 113-121, 2008

SILVA, A. A.; SILVA, J. F. Tópicos em plantas daninhas Viçosa, MG: Universidade Federal de Viçosa, 2007. 260 p.

TIMOSSI, P. C. Manejo de rebrotes de Digitaria insularis no plantio direto de milho. Planta Daninha, v. 27, n. 1, p. $175-179,2009$.

WELLER, S. Photosystem II inhibitors. In: Herbicide action course. West Lafayette: Purdue University, 2003. p. 131-184 